\title{
The Liberating Power of Commercial Marketing
}

Anker, Thomas Boysen; Kappel, Klemens; Sandøe, Peter

Published in:

Journal of Business Ethics

DOI:

10.1007/s10551-009-0236-4

Publication date:

2010

Document version

Publisher's PDF, also known as Version of record

Citation for published version (APA):

Anker, T. B., Kappel, K., \& Sandøe, P. (2010). The Liberating Power of Commercial Marketing. Journal of Business Ethics, 93(4), 519-530. https://doi.org/10.1007/s10551-009-0236-4 


\section{The Liberating Power of Commercial Marketing}

\author{
Thomas Boysen Anker \\ Klemens Kappel \\ Peter Sandoe
}

\begin{abstract}
The aim of this article is to explore the impact of commercial marketing on personal autonomy. Several philosophers argue that marketing conflicts with ideals of autonomy or, at best, is neutral to these ideals. After qualifying our concept of marketing and introducing the distinctions between (i) divergent and convergent marketing and (ii) being autonomous and acting autonomously, we demonstrate the heretofore unnoticed positive impact of marketing on autonomy. Specifically, we argue that (i) convergent marketing has a significant potential to reinforce autonomous action and (ii) divergent marketing has a significant potential to reinforce the state of being autonomous.
\end{abstract}

KEY WORDS: autonomous agency, being an autonomous person, divergent and convergent marketing, cultural values, critical reflection, first- and second-order desires

\section{Introduction}

The debate over the impact of marketing on personal autonomy predominantly concerns the degree to which marketing overrules autonomy. Commentators fall into two camps. The hardliners argue that marketing is hostile to autonomy and, more often than not, overrules the ability to develop and exercise personal autonomy (Barrett, 2000; Crisp, 1987; Raley, 2006; Sneddon, 2001), whereas the challengers argue that marketing is, to a considerable extent, compatible with the exercise of autonomy (Arrington, 1982; Cunningham, 2003). Both camps assume, however, that the impact of marketing on autonomy is negative or neutral, but never positive. In contrast, we argue that, under some circumstances, marketing can contribute positively to autonomous agency and the state of being autonomous.
First, we offer an initial clarification of the concepts of marketing and autonomy, which is essential to understanding the argument presented in this article. Later on, we provide a more detailed account of the concepts. According to the American Marketing Association (AMA, 2008), marketing is the activity for creating, communicating, delivering, and exchanging offerings that have value for customers, clients, partners, and society at large. The AMAdefinition is clearly a normative one in that marketing is not necessarily a vehicle for offerings that have value for consumers. Marketing certainly may, and quite often does, have value for consumers, but not always. However, taken as a normative statement about marketing that we should try to achieve in practice, the definition proves to be very useful.

We limit our focus to strategic marketing communications that attempt to induce a desire or preference by linking a commercial product or a corporate organization to a symbolic value or set of symbolic values in the mind of the consumer (e.g., branding).

The discussions in this article refer to, and build on, analyses of advertisements, but the arguments apply to any kind of marketing communication aimed at linking symbolic values to products. Thus, though we do not refer to them, we constantly keep in mind marketing communications such as wordof-mouth and viral marketing, product placements, events and sponsorships, which are suitable vehicles for linking products with symbolic values.

We will now turn to the question: what is personal autonomy? We distinguish between autonomous agency and the state of being autonomous.

Fundamental to our account of autonomous agency is the powerful idea that acting freely is a question of acting in accordance with and because of 


\section{Thomas Boysen Anker et al.}

one's own will or motivations. However, taken without qualifications, this basic idea is flawed because, in some cases, it allows persons acting on compulsions to be characterized as acting autonomously. For example, a drug addict could be said to act autonomously insofar as he or she wants the drugs and takes them exactly because of this want (Frankfurt, 1971; Lippert-Rasmussen, 2002).

One solution to the problem is to distinguish between various kinds of motivational elements or, put differently, to distinguish between a person's effective or immediate desires as opposed to his or her more fundamental ones. One way of doing so is to follow the lines of Frankfurt (1971) and introduce a distinction between first- and second-order desires, where a first-order desire expresses "what one wants" and a second-order desire expresses "what one wants to want." Against this qualification we hold that a person acts autonomously to the extent that his or her effective first-order desires match his or her more fundamental second-order ones.

Assuming that the aforementioned drug addict has a second-order desire not to take drugs, but that his first-order desire to take them is the stronger one, we can reasonably make the claim that he is acting against his own will and, therefore, not acting autonomously. (We elaborate on this account of autonomy in the section "How convergent marketing reinforces autonomy.”)

The concept of autonomous agency can also be illustrated similar to this: As Ted passes the bakery, a desire for a doughnut arises (first-order desire). However, Ted is concerned about his health; he believes that doughnuts are unhealthy, and, thus, he also wants not to buy a doughnut (second-order desire). Ted experiences a will-conflict. Our core idea of autonomous action holds that, if Ted's desire not to eat the doughnut is mostly important to him (i.e., if it is of the second-order) then he acts autonomously to the extent that he defeats his desire (of the first order) to buy the doughnut. And vice versa.

One challenge, some times referred to as the "source problem" (Lippert-Rasmussen, 2002), needs to be addressed. If a person acts on a fundamental second- order desire, which is acquired through some form of manipulation, say powerful marketing, he or she should not be said to act autonomously even though the effective first-order desire or motivation flows from the more funda- mental second-order one (Wolf, 1990). Our answer to this very strong objection is twofold.

First, the objection assumes that the ability to form one's desires independently of external influences is a requirement of autonomous agency. As Crisp (1987) notes, this requirement is certainly too strong because it is hardly believable that any of our actions flow from motivations that are totally in the control of our will and insensitive to external influences (e.g., socio-cultural determinants).

Second, the distinction between "identification" and "alienation" makes a difference as to whether or not acting on a manipulated desire counts as autonomous agency. The rationale is that an agent acting on a desire with which he or she identifies is acting wholeheartedly and, therefore, could not be said to act involuntary. Moreover, since none of our desires are formed independently of external influences, identification seems to be a reasonable criterion of autonomous agency (Frankfurt, 1988a, b; Lippert-Rasmussen, 2002). Accordingly, we suggest that an action flowing from an induced second-order desire is autonomous to the extent that the agent identifies with that second-order desire.

Now let us focus on the notion of being autonomous. On a coherentist account of autonomy, a person is autonomous to the extent that he or she assesses his or her fundamental desires and beliefs and endorses them in light of critical reflection (Buss, 2008). Autonomy, then, is a matter of a person's desires and beliefs being consistent with his or her reflective reasoning.

However, as was the case with the account of free agency outlined above, a strict coherentist account of being autonomous gives rise to the source problem, because induced desires might very well cohere with a fair deal of ones desires, beliefs and values even on critical reflection.

Most philosophers tend to hold that the requirements for being an autonomous person are stronger than the requirements for autonomous agency. Thus, identification is not a sufficient test, and we have to look for another solution. What is sometimes dubbed responsiveness-to-reason account of autonomy provides a strong answer to the source problem associated with the coherentist view of autonomy.

Roughly put, the responsiveness-to-reason account holds that an agent is autonomous if he or she 


\section{Liberating Marketing}

satisfies two requirements. First, autonomy requires the capability of stepping back from one's desires and values and critically reflecting on them. Second, autonomy requires the ability of changing one's life in response to this reflective reasoning (Buss, 2008; Christman, 1991; Dworkin, 1988; Mele, 1995; Wolf, 1990).

In order to illustrate the two notions of being autonomous, think of the case of Mark. Mark has a strong desire to become a professional footballer. However, on critical reflection, he does not endorse this desire because - to be perfectly honest to himselfhe does not have what it takes. Thinking coolly about his desire it occurs to him that having that desire might cause severe frustration in the long run. Mark would rather not like to have that desire.

On a strict coherentist account of autonomy, Mark is not autonomous with regard to his desire to be a footballer because it runs counter to other desires and is not consistent with his critical reasoning. Yet, on the responsiveness-to-reason account of autonomy, Mark will qualify as being autonomous if he tries to change his life in accordance with his critical reasoning, that is, if he tries to modify or repudiate his desire to be a footballer in response to his reasoning.

For the sake of the argument in this article, it is not important to argue in favor of one or the other account of being autonomous. The crucial thing is to illustrate that - across different influential accounts of autonomy - endorsing one's desires and values in light of critical reflection is a key property of autonomy.

The basic understanding of autonomous agency and being autonomous just outlined is a proper foundation for the discussion in this article because it appeals to two distinct and significant approaches to autonomy. On the one hand, our account of autonomous agency appeals to hedonistic intuitions because it claims that the satisfaction of (the right) desires is the single most important feature about autonomy. On the other hand, our account of being autonomous appeals to rationalistic intuitions because it claims that rational acceptance of one's desires is key.

In spite of this dual approach, we are aware that we cannot capture all significant approaches to autonomy. Most notably, we cannot account for important Kantian intuitions. For instance, if Sam is good to Sally - though he, at the bottom of his heart, desires to hurt her - then Sam exercises autonomy to a greater extent (on a Kantian account of autonomy) than he would have had he been good to Sally because he desired to be good to her (Kant, 2005). Sometimes, autonomy is about overriding one's desires - regardless of whether they match higher order desires or are endorsed in light of critical reflection.

To sum up: autonomous agency is a question of alignment or match between effective and fundamental desires, whereas being autonomous is a question of endorsement of one's fundamental desires in light of critical reflection. We elaborate on the concepts of being autonomous and acting autonomously later on.

\section{Three accusations against marketing}

We know of no argument that demonstrates a positive link between marketing and personal autonomy. Rather, the main background theories consist of arguments demonstrating that marketing compromises autonomy. In what follows, we briefly state the general tension between marketing and autonomy and then present influential accusations that marketing overrules either (i) the development of autonomy, (ii) autonomous action, or (iii) being an autonomous person.

Imagine, for example, that powerful marketing induces in Martha a strong effective desire to fulfill an ideal of beauty. On critical reflection, Martha finds the ideal rather oppressive and, as a consequence, she wants not to act on it and repudiates her desire to act so. However, due to the massive influence of marketing, her desire to fulfill the ideal remains effective and drives her to action. In this case, marketing overrules both (i) autonomous agency (because it makes the agent act on an effective desire that runs counter to her fundamental desires) and (ii) being an autonomous person (because it makes the agent hold a desire that she repudiates in light of critical reflection).

Let us now turn to the distinct accusations.

Raley (2006) claims that advertising to children erodes their ability to develop into autonomous persons. She distinguishes between three properties of autonomy: authenticity (convergence between 


\section{Thomas Boysen Anker et al.}

choices and desires), independence (freedom from coercion), and competence (the ability to evaluate choices rationally). Her charge is that marketing to children contains claims that are supported by irrational types of evidence and arguments and that children take up this irrational line of reasoning as a regulative ideal because they are very literal minded and understand ads as literal truths. As a result, ads impoverish children's ability for rational reasoning (her third property of autonomy).

Crisp (1987) claims that marketing undermines the basis for autonomous action. Basically, his argument rests on two premises. First, rational decision making, where agents weigh competing reasons for doing or omitting an action, is a precondition for autonomous agency. Second, marketing communications that associatively link values - which are not an integral part of the product or organization's functionality - to products, and organizations tend to induce desires in consumers without their knowledge. Crisp draws the conclusion that, when driven by such unknown or subconscious marketing induced desires, the consumer never has the opportunity to weigh the reasons for so acting - and thereby violates a necessary precondition for autonomy - because the subconscious nature of the desires makes them epistemically inaccessible.

For Sneddon (2001), autonomy involves assessing whether (i) our values are consistent with our desires and (ii) our values are desirable. The second condition - which he takes to be the most valuable property of autonomy - requires access to values distinct from one's own and an openness to consider other ways of living. And it is precisely this requirement (access to alternate values and openness to other ways of living) that Sneddon believes marketing undermines. The core of the argument is the claim that marketing has an inherent tendency to promote a narrow, uniform set of values (all based on the meta-value of consumption) and thus necessarily homogenizes the cultural horizon of alternate values necessary for being autonomous (i.e., reflecting critically on the desirability of one's values).

Note, that we will not discuss whether we find the accusations justified or not, since, even if they are justified, it does not affect our arguments. We would certainly have to contradict arguments showing that being subject to marketing turns a person - on the whole - into a non-autonomous being, but not even the hardliners' argument is that strong. Sneddon (2001), for instance, who makes the rather strong claim that marketing harms both the ability for developing autonomy as well as the option for exercising it, does so without holding that marketing entirely eliminates personal autonomy. We do not take it to be necessary to refute the arguments of the hardliners because we assume - based on the actual arguments of the hardliners - that being subject to marketing that is hostile to one's autonomy does not rule out having autonomy at the same time but in another respect.

\section{Convergent and divergent marketing}

In the course of writing this article, we analyzed various brands, advertisements, and product placements. We discovered a very basic distinction between two types of marketing or two ways of linking values to products and organizations. We have not been able to find any articles or textbooks that describe the distinction, and so in what follows, we name and describe the distinction.

The distinction concerns the way marketing communications address the consumer. Convergent marketing, on the one hand, addresses the consumer as he or she is and tries to target the consumer's actual set of beliefs, desires, hopes, dreams, and so forth. Divergent marketing, on the other hand, tries to change the personal identity of the consumer by transforming his or her web of beliefs, desires, hopes, dreams, and so forth. Convergent marketing that, say, appeals to the consumer's dream universe tries to link a product or organization to the consumer's actual dream of $\mathrm{X}, \mathrm{Y}, \mathrm{Z}$. In contrast, divergent marketing would try to transform the consumer's actual dream universe of $\mathrm{X}, \mathrm{Y}, \mathrm{Z}$ into a dream of $\mathrm{A}, \mathrm{B}, \mathrm{C}$ and then link the product or organization to that new dream universe.

The formal definitions of convergent and divergent marketing are as follows:

Convergent marketing attempts to induce a desire or preference by triggering the consumer's actual values and making him or her associate these values with a product or organization. The strategic marketing communications intentionally converge on the consumer's value system. 


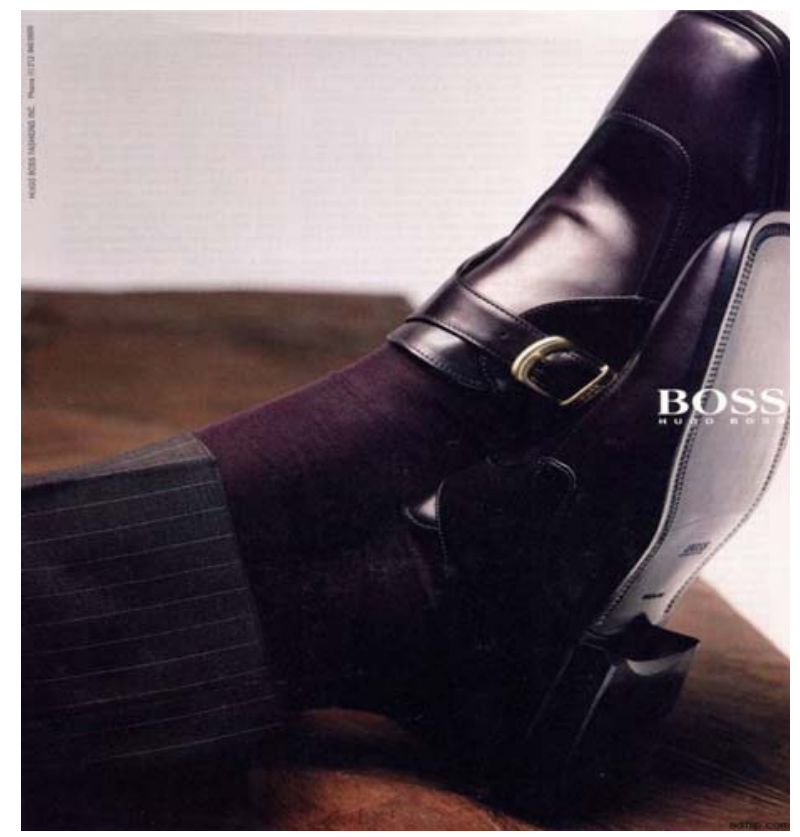

Figure 1. Boss.

The ad for Boss shoes (Figure 1) illustrates the nature of convergent marketing because it does not introduce new values but appeals to the existing view of the businessman as a person with power, success, and wealth.

Divergent marketing attempts to induce a desire or preference by creating new values in the mind of the consumer and making him or her associate those new values with a product or an organization. Aiming to transform the consumer's value system, the strategic marketing communications intentionally diverge from the consumer's value system.

The ad for Dove (Figure 2) is an instance of divergent marketing in that Dove (i) intentionally attempts to change the way the target group views beauty to create a more inclusive, less stereotyped ideal of beauty and (ii) tries to make the consumer feel or believe that Dove's product line facilitates this new value of "real beauty" (Dove, 2007).

It will prove useful to consider how to draw the line between divergent and convergent campaigns as well as saying a few words about the frequency of the two types of marketing.

Convergent and divergent marketing are not absolute concepts. A marketing campaign can be convergent or divergent to a greater or lesser degree. Moreover, a campaign might incorporate elements

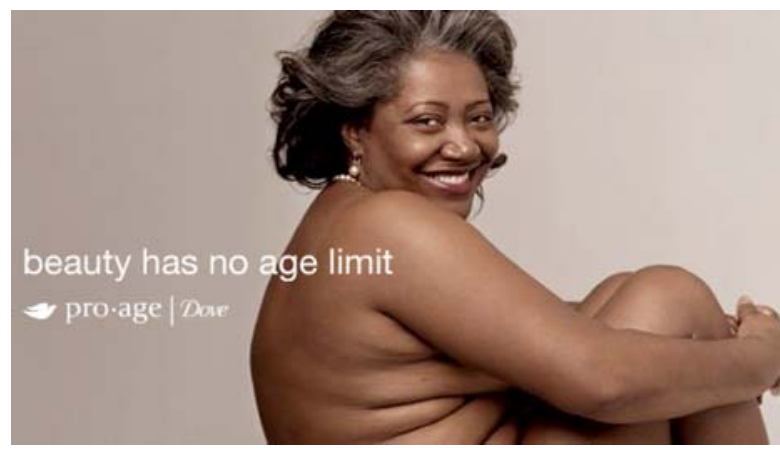

Figure 2. Dove.

of both a convergent and divergent approach. Along these lines, one might argue that the ad for Boss shoes is not only convergent, as illustrated above, but also partly divergent insofar as some consumers might not associate being in business with the values conveyed by the ad. This observation leads to the question of how we decide whether an ad is principally convergent or divergent. Three suggestions are at hand.

One could hold that whether a campaign is divergent or convergent comes down to (i) how the individual consumer perceives the ad (subjectivism); or (ii) how the target group perceives the ad (intersubjectivism); or (iii) the purpose of the message that the ad agency/company wants to communicate (intentionalism). We suggest distinguishing between convergent and divergent campaigns in terms of how the target group conceives of the ad (intersubjectivism). Our rationale is twofold.

First, imagine a case where a very small group of consumers experience a campaign, say the ad for Boss shoes, to be divergent whereas most others or even all other consumers conceive of it as being convergent. In cases such as this where the distribution of perception is very asymmetric, it seems odd to buy into the subjectivist conclusion that the campaign is both convergent and divergent or vice versa. A more proper answer would be to say that we are dealing with a convergent campaign but that a number of consumers do not experience it to be so.

Second, intentionalism seems implausible because it allows for a campaign, which most or even all consumers experience as, say, convergent to be characterized as divergent if that is what it was intended to be. And vice versa. This is not credible. If a campaign, such as the one for Boss shoes, was 
intended to be divergent, but most consumers and, indeed, the ones in the target group conceived of it as being convergent, then it would be fair to say that the message did not come across; rather than that the campaign is divergent though consumers experience it as being convergent.

With regard to the prevalence of convergent and divergent marketing, we have no statistical data. However, it is worth noting that commercial marketing and global branding are quite often accused of homogenizing the "value horizon," i.e., the total set of values in a culture at a given time (Sneddon, 2001; Waide, 1987). Most notably, Ritzer proposes his McDonaldization thesis that marketing and global branding have a significant power to even out cultural diversity (Ritzer, 1998, 2006). This criticism suggests that it is quite commonplace to assume that the nature of commercial marketing is, by and large, convergent. See, for instance, Miller (1995) or Gabriel and Lang (2006) for illuminating discussions of the influence of marketing on cultural values.

Dove's "Campaign for Real Beauty" is probably one of the most clear-cut examples of divergent marketing, but the very enterprise of divergent marketing is by no means a rarity. Ikea launched a marketing campaign in Spain, which encourages people to break the societal rules that govern our use of colors and patterns, among others, by encouraging men to use "women-colors" such as red, cherry, and pink (see Figure 3). In a marketing campaign consisting of national flags, in which the colors on the various flags symbolize a striking social or political issue, the Portuguese news magazine Grande Reportagem invites the consumer to reflect on political issues such as just distribution (see Figure 4). The black and the red colors that take up the majority of the space on the flag represent people infected by HIV and malaria. The tiny bit of yellow represents people with access to medical care. United Colors of Benetton has won a number of awards for their thought-provoking campaigns that clearly intend to make the consumer reflect on social, cultural, and political issues. One telling example is the "Angel and Devil" campaign featuring a white girl and a black boy. The black boy's hair is styled into horns, thereby establishing a direct reference to the Devil. The campaign obviously intends to confront cultural prejudice and make the consumer reflect on and evaluate his or her actual beliefs (see Figure 5).

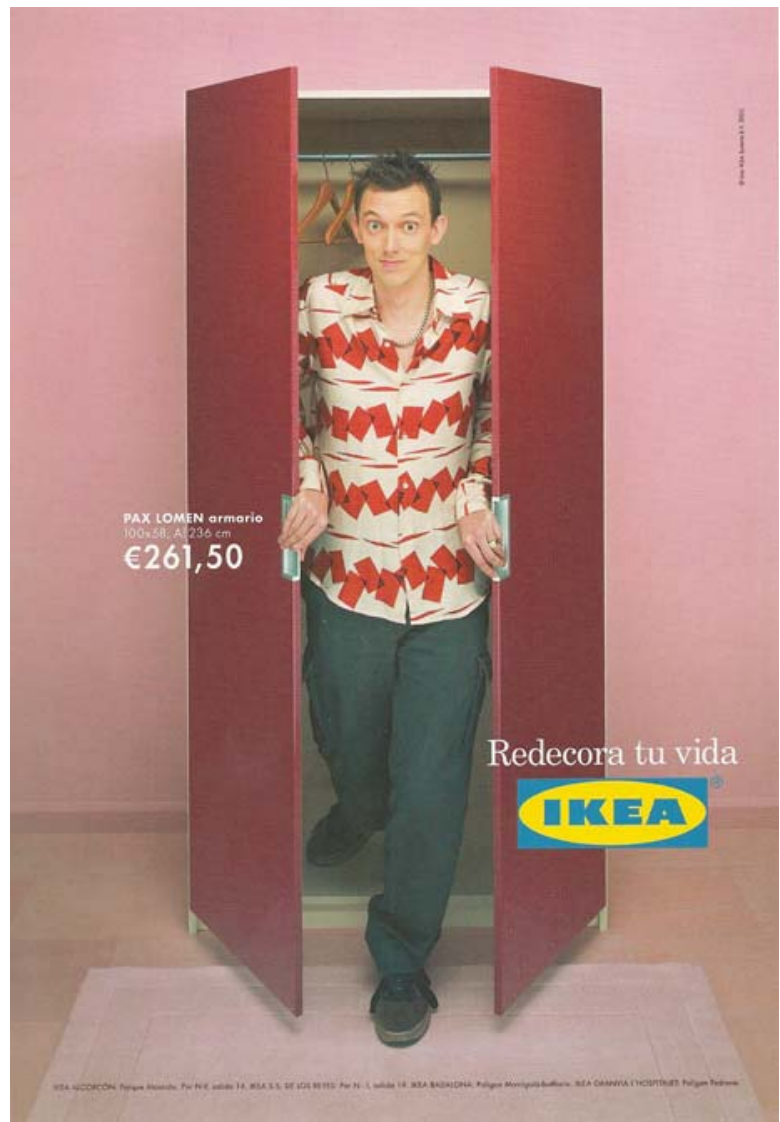

Figure 3. Ikea.

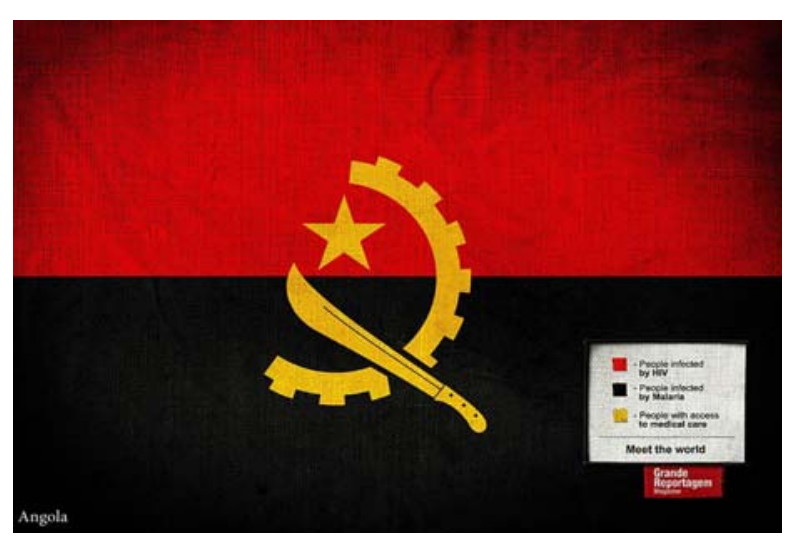

Figure 4. Grande Reportagem.

All of above mentioned marketing campaigns are instances of divergent marketing because they either try to break down or confront existing cultural values rather than just affirm the consumer's actual 


\section{Liberating Marketing}

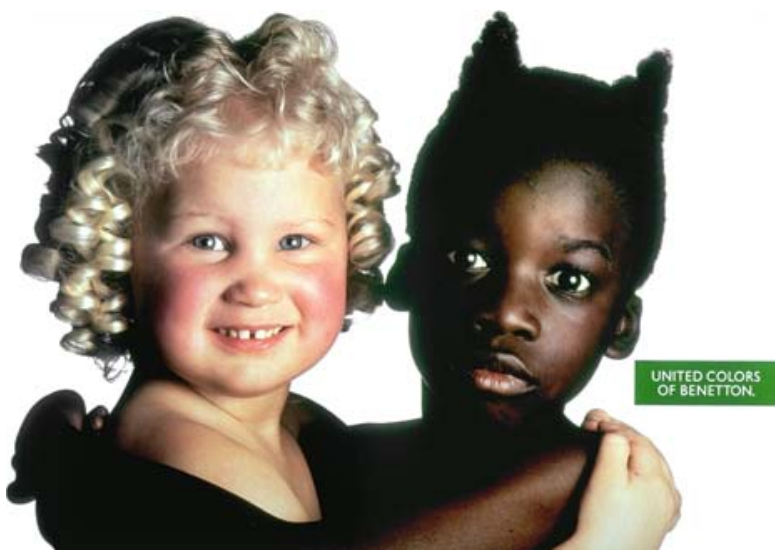

Figure 5. Benetton.

value universe, as would have been the case with convergent marketing.

In the next two sections, we put forward our arguments in favor of a positive link between marketing and autonomy.

\section{How convergent marketing reinforces autonomy}

In this section, we argue that convergent marketing may reinforce autonomous agency. The argument builds on Frankfurt's (1971) hierarchical theory of free or autonomous agency that continues to influence much of the contemporary philosophical study on autonomy (Arpaly and Schroeder, 1999; Boysen, 2004; Lippert-Rasmussen, 2002; Rosner, 2000; Rostbøll, 2004; Stump, 1988; Watson, 1975). In order to understand the hierarchical account of freedom and understand why it is "hierarchical," it is critical first to clarify the distinction between firstand second-order desires.

A first-order desire refers to an action and has the form "A wants to X," where " $A$ " stands for an agent and " $X$ " for an action. A second-order desire refers to a first-order desire and has the form "A wants to want to X." Effective first-order desires drive an agent all the way to action, whereas second-order desires are not in themselves effective (Frankfurt, 1971, pp. 7-10). A crucial feature is that the two levels of desires are independent: one can have one without the other, and the levels need not be in harmony. For instance, an agent may have a first- order desire to X even though he or she has a conflicting second-order desire not to desire to $\mathrm{X}$. That was exactly what happened to Ted in our previous example: he had a desire for a doughnut but also a desire not to have that desire. Another important aspect is that second-order desires are more deeply integrated in the agent's self in the sense that the agent identifies more deeply with his or her secondorder desires than with his or her first-order desires (Frankfurt, 1971, p. 13). ${ }^{1}$ Accordingly, Frankfurt frequently conceptualizes second-order desires with which the agent identifies him- or herself as "true desires" reflecting what the agent "really wants."

Having laid out this background information, we can now state our concept of autonomous action. An agent acts autonomously to the extent that he or she acts on a first-order desire that matches a secondorder desire with which the agent identifies him- or herself. Perhaps, it seems superfluous to state that the agent has to identify him- or herself with the second-order desire, but agents may have distorted second-order desires that they feel estranged from. Intuitively, acting on estranged second-order desires cannot count as autonomous agency, insofar as no one really desires to be alienated from one's doings.

Note that the direction of match or alignment between first- and second-order desires is decisive. If an agent adjusts his or her first-order desires to his or her second-order desires and acts accordingly, then he or she acts autonomously. However, if the agent adjusts his or her second-order desires to his or her first-order desires and acts accordingly, then he or she does not act autonomously. The proper match or alignment is a top-down process. The rationale is that second-order desires reflect what the agent really or truly wants, whereas first-order desires may only reflect trivial or even undesirable desires. On this background, philosophers often refer to the different variants and developments of this theory of autonomy as "hierarchical accounts of autonomy."

We now turn to a scenario that demonstrates the positive impact that convergent marketing may have on autonomous agency.

Terry is an IT-consultant, spending long hours in front of his laptop and in his car driving to see clients. During the last couple of years, Terry has had increasing problems with his diet and by now he is quite overweight. In his own view, he consumes on the way too many soft drinks and too much 


\section{Thomas Boysen Anker et al.}

unhealthy fast food, such as burgers and pizza. He really wants to do something about the problem, but he has not succeeded in motivating himself to actually choose a healthier life style.

Terry has a second-order desire to take on a healthier lifestyle (e.g., buy and consume healthy foods), but he cannot bring about an efficient firstorder desire to actually do this. According to our interpretation of autonomous action, Terry's inability to motivate himself to do what he really wants to do (that is, to act on a particular set of second-order desires) turns Terry into a non-autonomous agent (in relation to that specific set of second-order desires).

Now, imagine that Terry is subject to a series of extraordinarily effective marketing campaigns featuring a character heavily associated with health, whom Terry conceives of as a role model. The campaign goes on for weeks and has a significant power to induce desires for healthy living. As a consequence, Terry is effectively motivated to take on a healthier life style, i.e., he is motivated to actually buy and eat more fruits and vegetables and consume fewer soft drinks and less fast food.

Deploying the terminology of first- and secondorder desires, one can say that the marketing campaign induces effective first-order desires that match a set of second-order desires with which Terry identifies himself and on which he would not have acted had he not been subject to the brand campaign. In other words, the marketing campaign makes it possible for Terry to act on significant second-order desires and thereby brings to life a set of autonomous actions that were otherwise inaccessible to Terry because he could not form the corresponding effective first-order desires of his own will.

How will the hardliners who claim that marketing undermines autonomy respond to this argument?

Hardliners relying on a hierarchical account of autonomy will have to bite the bullet because we arrive at our conclusion from their assumptions about autonomy and marketing. The assumptions are that (i) autonomous action is a question of aligning first-order desires with second-order ones and (ii) effective marketing induces desires for buying products.
Hardliners sympathetic to the rationalistic concept of autonomy outlined above will hold that something more than identification is needed in order to turn a match between first- and second-order desires into genuine autonomy. Specifically, they will argue that a match between a first- and a second-order desire qualifies as autonomy only if the agent holds the first-order desire in light of and because of rational assessment and endorsement of the secondorder desire in question. And Terry quite obviously does not hold his newly formed first-order desire for healthy products because of critical assessment and endorsement of his second-order desire to lead a healthy life. The causal explanation of the formation of his first-order desire lies in the fact that he has been subject to marketing, and, consequently, the example of Terry does not show that marketing can enhance autonomy.

In reply to this, consider the following. First, one might fear that the requirement of critical assessment and endorsement is so strong that it reduces autonomous agency to a very marginal human phenomenon. Whether this is so is an empirical matter that we cannot settle here.

Second, consider situations where an agent cannot bring about first-order desires that correspond to some of his or her key second-order desires. Here it is rational to prefer marketing-induced firstorder desires that match the second-order desires in question because the alternative is an incapability to do what one really wants to do. Hence, if marketing of healthy food can make Terry do what he really wants to do (and if he cannot do this on his own), then why should he - as a rational agent choose not to be subject to marketing of healthy food?

\section{How divergent marketing reinforces autonomy}

In this section, we argue that divergent marketing may reinforce the state of being autonomous. The argument builds on the rationalistic account of being an autonomous person set forth by Sneddon (2001). The account is heavily influenced by the works of Taylor (1985a, b) and roughly parallel to the concept of autonomy found in Rawls (1971, pp. 513-520) and Dworkin (1988). 


\section{Liberating Marketing}

An agent is autonomous to the extent that he or she assesses:

(i) What his or her values are and whether his or her first-order desires are consistent with these values.

(ii) Whether the values themselves are desirable (Sneddon, 2001, p. 18).

Thus, being autonomous involves more than the matching of first-order desires with second-order desires. But what more is needed? Sneddon answers as follows:

The exercise of ... autonomy requires the assessment of the structure of one's life against the background of other actual and possible ways of living (2001, pp. 18-19).

The root idea is that an agent is autonomous to the extent that he or she endorses her basic values after having subjected them to a rational process of critical evaluation in light of other possible values or other ways of living. On this basis, Sneddon claims that marketing as such undermines autonomy in two ways. First, by homogenizing the horizon of values that the individual can access to reflect critically on the desirability of her own values. Second, by counteracting the willingness to exercise autonomy (i.e., to engage in critical reflection on one's values).

Here is an illustrating quote:

Instead of portraying ways of living significantly different from those being lived by the people exposed to advertising, advertisers will be rewarded by tapping into what already appeals to people living these sorts of life (2001, p. 22).

And he concludes that "advertising, as an institution devoted to the strengthening of one way of living, works against having knowledge of other ways of living (2001, p. 22)." As mentioned in the section "Convergent and divergent marketing," the view that marketing is a process of cultural homogenization is far from peripheral.

In what follows, we will provide an analysis of a set of ads that clearly demonstrate that - given Sneddon's account of autonomy - divergent marketing may contribute positively to important properties of autonomy.

Dove's brand campaign "Campaign for Real Beauty" is not just a paradigm case of divergent marketing. The campaign is also a clear-cut example of divergent marketing that reinforces autonomy. Dove goes upstream and presents wrinkled, chubby and gray-haired models that under normal conditions would not have found their way to the billboards of the cityscape. Take, for instance, the ad of the charismatic, wrinkled woman (see Figures 6, 7).

The text says: "When did beauty become limited by age? It's time to think, talk and learn how to make beauty real again. Join Dove and the debate at campaignforrealbeauty.com."

The same figure goes with an alternate text: "Wrinkled? Wonderful? Can 96 be beautiful? Text your vote to 43683 [4Dove] (A) for wrinkled. (B) for wonderful."

Two things are decisive about these ads. On the one hand, Dove explicitly encourages the persons exposed to the ads to reflect upon the relation between beauty, age, and being wrinkled. (In another set of ads, they invite us to reflect on the relation between body-size and attractiveness). On the other hand, Dove is not just facilitating a debate; they are

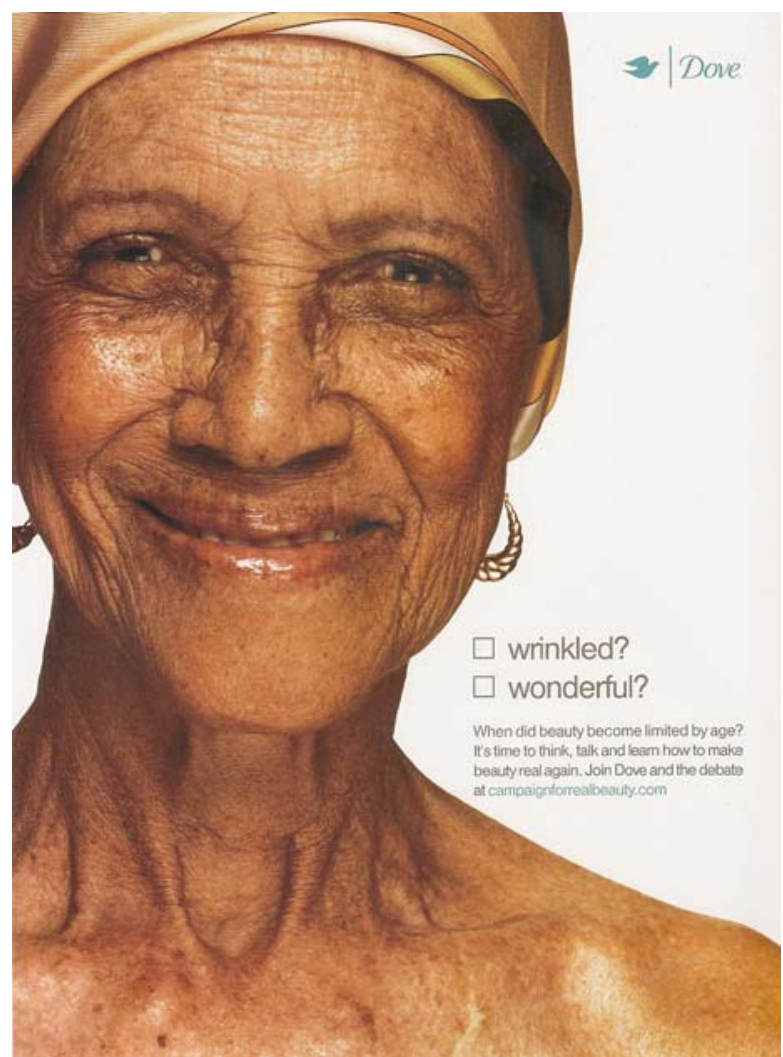

Figure 6. Dove. 


\section{Thomas Boysen Anker et al.}

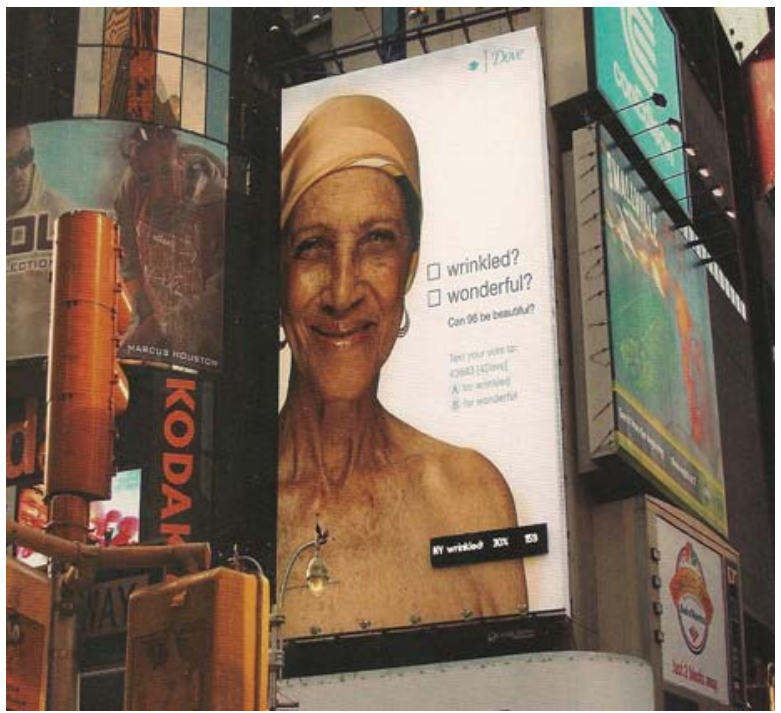

Figure 7. Dove.

active players who take a stance. Their official mission is to change the way society views beauty to create a more inclusive ideal of beauty that does not thwart women's self-esteem. Dove is actually trying to make a new and more inclusive ideal of beauty.

In this way, Dove actually promotes, or seeks to promote, two properties of autonomy that Sneddon claims to be at odds with marketing. First, the brand campaign encourages reflection on one's values in light of relevantly different alternate values. Second, the brand campaign proposes new and relevantly different cultural values that provide a proper background for assessing the desirability of one's values and desires.

What would Sneddon reply to this? Perhaps that divergent marketing only apparently reinforces important properties of autonomy. Dove, the argument goes, introduces a new ideal of beauty designed to improve the bases of self-esteem, but only apparently so, because the true purpose of the brand campaign is to emphasize the value of consumption and raise profits.

In response to this, we will note two points. First, our purpose is to show that marketing can contribute positively to personal autonomy, and this point remains unaffected by the envisaged objection. Second, though it is true that the motive behind an action sometimes determines the normative status of that action, the motive is not significant in all situ- ations. When we want to praise or blame a person or an organization, the motive behind the relevant set of actions is often crucial, but this does not imply that actions having overall good consequences are non-moral actions just because "moral good" or "empathetic concern" is not the primary driving motive behind these actions. Thus, it is meaningful to hold that Dove does not deserve moral praise for its "Campaign for Real Beauty" (because the driving motive after all is making a profit), but it is erroneous to conclude that the campaign is without positive moral significance (in so far as it reinforces autonomy and thereby brings about a moral good to some consumers).

Yet, even though we acknowledge the meaningfulness of not attributing praise to Dove insofar as their driving motive is making a profit, we actually do believe that their campaign deserves moral praise because we assume that they could have chosen to create an alternative campaign having the same economic impact, but without any positive social impact.

\section{Concluding remarks}

Prior research on marketing and personal autonomy has either focused on how and why many modern types of marketing conflict with personal autonomy (this is by far the most predominant approach) or tried to demonstrate how and why these types of marketing are, after all, very often compatible with autonomy. In contrast, the purpose of this article was to pursue a positive link between marketing and autonomy. Thus, we have argued that marketing has a potential to reinforce autonomous agency and the state of being an autonomous person.

First, we outlined a hierarchical theory of autonomous action that, by and large, holds that an agent acts autonomously to the extent that he or she acts on effective desires (first-order desires) that accord with what he or she really wants (second-order desires). Then we constructed a hypothetical scenario that - given the account of autonomy - intuitively demonstrated how marketing could reinforce autonomous agency.

Second, we sketched a rationalistic theory of being an autonomous person that, roughly speaking, takes a person to be autonomous to the extent that 


\section{Liberating Marketing}

he or she endorses his or her personal desires and values after having subjected them to rational, critical reflection. We carried out an analysis of a marketing campaign that - given the account of autonomy - intuitively demonstrated how marketing could reinforce significant properties of being an autonomous person.

\section{Note}

1 It is a logical possibility that an agent identifies himor herself most deeply with his or her first-order desires. That possibility is an interesting borderline case, but it is beyond the scope of this article to pursue the point any further.

\section{Acknowledgments}

The authors would like to thank the peer reviewers for helpful comments. Moreover, we are grateful to our colleagues Polymeros Chrysochou, Dorthe Brogaard Kristensen, Morten Andreasen, and Claus Strue Frederiksen for their inspiring input.

\section{References}

AMA (American Marketing Association): 2008, 'Marketing Definitions', http://www.marketingpower.com/ AboutAMA/Pages/DefinitionofMarketing.aspx. Accessed May 2008.

Arpaly, N. and T. Schroeder: 1999, 'Praise, Blame and the Whole Self, Philosophical Studies 93, 161-188.

Arrington, R. L.: 1982, 'Advertising and Behaviour Control', Journal of Business Ethics 1(1), 3-12.

Barrett, R.: 2000, 'Market Arguments and Autonomy', Journal of Philosophy of Education 34(2), 327-341.

Boysen, T.: 2004, 'Death of a Compatibilistic Intuition', Sats - Nordic Journal of Philosophy 5(2), 92-104.

Buss, S.: 2008, 'Personal Autonomy', in E. N. Zalta (ed.), The Stanford Encyclopedia of Philosophy, http:// plato.stanford.edu/entries/personal-autonomy/. Accessed August 2009.

Christman, J.: 1991, 'Autonomy and Personal History', Canadian Journal of Philosophy 21, 1-24.
Crisp, R.: 1987, 'Persuasive Advertising, Autonomy, and the Creation of Desire', Journal of Business Ethics 6(5), 413-418.

Cunningham, A.: 2003, 'Autonomous Consumption: Buying Into the Ideology of Capitalism', Journal of Business Ethics 48(3), 229-236.

Dove: 2007, http://www.campaignforrealbeauty.com/. Accessed August 2009.

Dworkin, G.: 1988, The Theory and Practice of Autonomy (Cambridge University Press, Cambridge).

Frankfurt, H. G.: 1971, 'Freedom of the Will and the Concept of a Person', Journal of Philosophy 68(1), 5-20.

Frankfurt, H. G.: 1988a, 'Identification and Externality', in The Importance of What We Care About (Cambridge University Press, Cambridge), pp. 58-68.

Frankfurt, H. G.: 1988b, 'Identification and Wholeheartedness', in The Importance of What We Care About (Cambridge University Press, Cambridge), pp. 159178.

Gabriel, Y. and T. Lang: 2006, The Unmanageable Consumer (Sage Publications, London).

Kant, I.: 2005, Groundwork for the Metaphysics of Morals (Broadview Press, Peterborough, ON).

Lippert-Rasmussen, K.: 2002, 'Real-Self Accounts of Freedom', Sats - Nordic Journal of Philosophy 3(2), 5072.

Mele, A.: 1995, Autonomous Agents: From Self-Control to Autonomy (Oxford University Press, New York).

Miller, D. (ed.): 1995, Acknowledging Consumption (Routledge, London/New York).

Raley, Y.: 2006, 'Food Advertising, Education, and the Erosion of Autonomy', The International Journal of Applied Philosophy 20(1), 67-79.

Rawls, J.: 1971, A Theory of Justice (Clarendon Press, Oxford), pp. 513-520.

Ritzer, G.: 1998, The McDonaldization Thesis: Explorations and Extensions (Sage Publications, London).

Ritzer, G. (ed.): 2006, McDonaldization: The Reader (Pine Forge Press, Thousand Oaks, CA).

Rosner, J. A.: 2000, 'Reflective Endorsement and the Self: A Response to Arpaly and Schroeder', Philosophical Studies 101, 107-112.

Rostbøll, C. F.: 2004, 'Freedom as Satisfaction? A Critique of Frankfurt's Hierarchical Theory of Freedom', Sats - Nordic Journal of Philosophy 5(1), 131-146.

Sneddon, A.: 2001, 'Advertising and Deep Autonomy', Journal of Business Ethics 33(1), 15-28.

Stump, E.: 1988, 'Sanctification, Hardening of the Heart, and Frankfurt's Concept of Free Will', Journal of Philosophy 85(8), 395-420. 


\section{Thomas Boysen Anker et al.}

Taylor, C.: 1985a, 'Self-Interpreting Animals', in C. Taylor (ed.), Human Agency and Language: Philosophical Papers 1 (Cambridge University Press, Cambridge).

Taylor, C.: 1985b, 'What is Human Agency?', in C. Taylor (ed.), Human Agency and Language: Philosophical Papers 1 (Cambridge University Press, Cambridge).

Waide, J.: 1987, 'The Making of Self and World in Advertising', Journal of Business Ethics 6, 73-79.
Watson, G.: 1975, 'Free Agency', Journal of Philosophy 72(8), 205-220.

Wolf, S.: 1990, Freedom Within Reason (Oxford University Press, New York).

University of Copenhagen, Copenhagen, Denmark E-mail: tba@hum.ku.dk 